Slavica

bruxellensia

\section{Slavica bruxellensia}

Revue polyphonique de littérature, culture et histoire

slaves

9 | 2013

Érotisme

\title{
Elżbieta Z. Wichrowska, Twoja Śmierć. PoczĄtki dziennika intymnego w Polsce na przełomie XVIII i XIX wieku (Ta Mort. Les débuts du journal intime en Pologne au tournant des $\mathrm{XVIII}^{\mathrm{e}}$ et $\mathrm{XIX}^{\mathrm{e}}$ siècles)
}

\section{Francesco Annicchiarico}

\section{OpenEdition}

\section{Édition électronique}

URL : http://journals.openedition.org/slavica/1381

DOI : $10.4000 /$ slavica. 1381

ISSN : 2034-6395

Éditeur

Université libre de Bruxelles - ULB

\section{Référence électronique}

Francesco Annicchiarico, «Elżbieta Z. Wichrowska, Twoja Śmierć. Początki dziennika intymnego w Polsce na przełomie XVIII i XIX wieku (Ta Mort. Les débuts du journal intime en Pologne au tournant des XVIII' et XIXe siècles) », Slavica bruxellensia [En ligne], 9 | 2013, mis en ligne le 15 avril 2013, consulté le 22 septembre 2020. URL : http://journals.openedition.org/slavica/1381 ; DOI : https://doi.org/ 10.4000/slavica.1381

Ce document a été généré automatiquement le 22 septembre 2020.

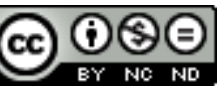

Les contenus de Slavica bruxellensia sont mis à disposition selon les termes de la Licence Creative Commons Attribution - Pas d'Utilisation Commerciale - Pas de Modification 3.0 France. 
Elżbieta Z. Wichrowska, Twoja Śmierć. Początki dziennika intymnego $w$ Polsce na przełomie XVIII i XIX wieku (Ta Mort. Les débuts du journal intime en Pologne au tournant des $\mathrm{XVIII}^{\mathrm{e}}$ et XIX ${ }^{\mathrm{e}}$ siècles)

Francesco Annicchiarico

\section{RÉFÉRENCE}

Elżbieta Z. Wichrowska, Twoja Śmierć. PoczĄtki dziennika intymnego $w$ Polsce na przełomie XVIII $i$ XIX wieku, Spectrum Press, 2012. 
1 Antoni Ostrowski, noble et général de l'armée polonaise, politicien engagé dans les terribles événements politiques du $\mathrm{XIX}^{\mathrm{e}}$ siècle, était aussi homme de lettres homo scribens - qui s'est consacré à l'écriture de ses propres mémoires. Ses journaux intimes furent publiés à Paris en 1836. Dans Twoja Śmierć. PoczĄtki dziennika intymnego $w$ Polsce na przełomie XVIII $i$ XIX wieku (Ta Mort. Les débuts du journal intime en Pologne au tournant des XVIII ${ }^{\mathrm{e}}$ et $\mathrm{XIX}^{\mathrm{e}}$ siècles), Elżbieta $\mathrm{Z}$. Wichrowska, historienne de la littérature et de la culture polonaises, s'est intéressée à deux recueils d'Ostrowski encore inédits en Pologne, ainsi qu'à sa correspondance.

2 Dans ce volume, l'auteure analyse les journaux écrits par Ostrowski pendant les

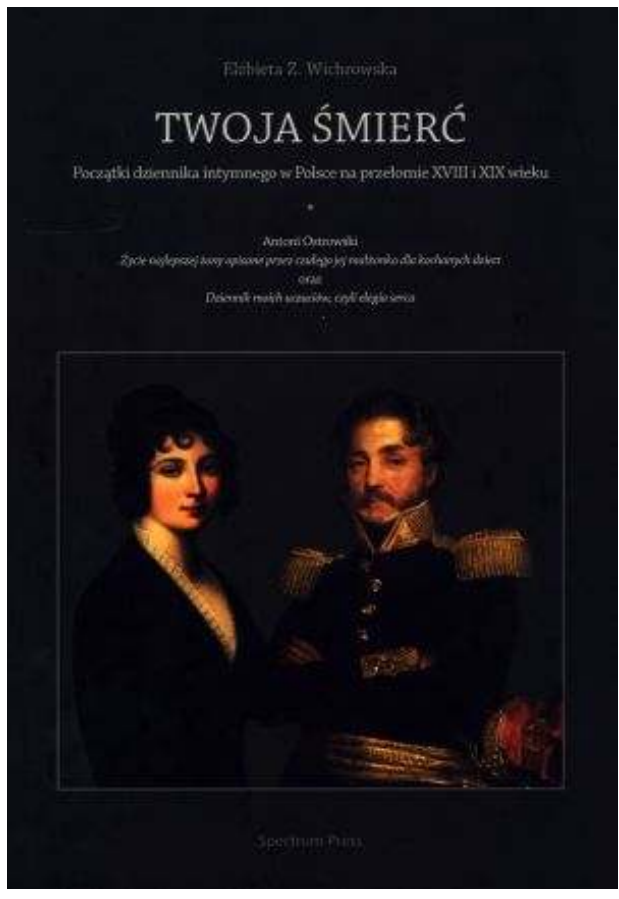
guerres du XIX ${ }^{\mathrm{e}}$ siècle, et en particulier les lettres que il adressait à son épouse décédée. Celles-ci composent deux œuvres différentes éditées in extenso dans l'ouvrage de Wichrowska : Życie najlepszej żony opisane przez czułego jej małżonka dla kochanych dzieci (Vie de la meilleure des femmes décrite par son tendre époux à l'attention de leurs chers enfants), recueil de textes qui évoque la perte prématurée de Józefa Ostrowska, épouse de l'auteur, et Dziennik moich uczuciów, czyli elegia serca (Journal de mes sentiments, ou élégie de mon cœur), œuvre dans laquelle Ostrowski exprime ses sentiments les plus purs envers sa femme bien-aimée.

3 Outre leur forte valeur historique qui réside dans la description de l'environnement politique et social de la Pologne du XIX ${ }^{\mathrm{e}}$ siècle, les mémoires d'Ostrowski sont présentés comme un journal occupant une position clef dans les lettres polonaises du XIX ${ }^{\mathrm{e}}$ siècle.

Ces deux œuvres, précédées d'un appareil critique, constituent la seconde partie de l'ouvrage. La première partie est quant à elle tout d'abord consacrée à une mise au point critique sur le journal polonais au seuil du XIX $^{\mathrm{e}}$ siècle, dans lequel l'auteure propose une éclairante typologie illustrée d'exemples. L'auteure se livre ensuite à une analyse de la biographie épistolaire et de la correspondance intime par le biais des œuvres d'Ostrowski. Par sa lecture questionnant la langue de ces textes, leur style et les conventions du journal en Pologne et par l'analyse de ses principales thématiques, Wichrowska offre un nouveau point de vue replaçant la littérature des mémoires dans une nouvelle perspective au sein de l'histoire des lettres polonaises : en examinant les relations entre la pratique de l'écriture personnelle et les autres formes littéraires. La langue d'Ostrowski, en tant que moyen d'expression des sentiments et donc langage intime entre l'auteur et son épouse, avec Dieu, sa patrie, ses enfants, mais encore plus avec sa propre personne, constitue aux yeux de l'auteure le signe d'une évolution des rapports homme/femme et l'annonce d'un nouveau type d'écriture des mémoires.

5 L'ouvrage est le fruit du travail méthodique de l'auteure qui s'est consacrée à déchiffrer les lettres autographes d'Ostrowski ainsi que ses manuscrits originaux: un travail méticuleux qui a non seulement le mérite de faire connaître des textes jusque-là 
inédits, mais aussi d'enrichir l'analyse du journal d'un point de vue très précis. Le livre a été conçu à partir d'un travail conséquent de recherches dans les archives de Pologne et d'Ukraine, travail qui a permis de faire découvrir des documents jamais encore utilisés dans la recherche, comme par exemple la correspondance qui date de la période de la Grande Diète et du Duché de Varsovie.

6 L'édition est enrichie d'illustrations : reproductions de lettres et de textes originaux, tableaux présentant l'auteur et son épouse, et vues du palais dans lequel la famille demeurait. Enfin, l'ouvrage est doté d'un utile index des noms facilitant la lecture.

INDEX

Index géographique : Pologne

Mots-clés : journal intime, littérature polonaise, mémoires

Index chronologique : XIXe siècle, XVIIIe siècle

\section{AUTEURS}

FRANCESCO ANNICCHIARICO

Traducteur littéraire 